
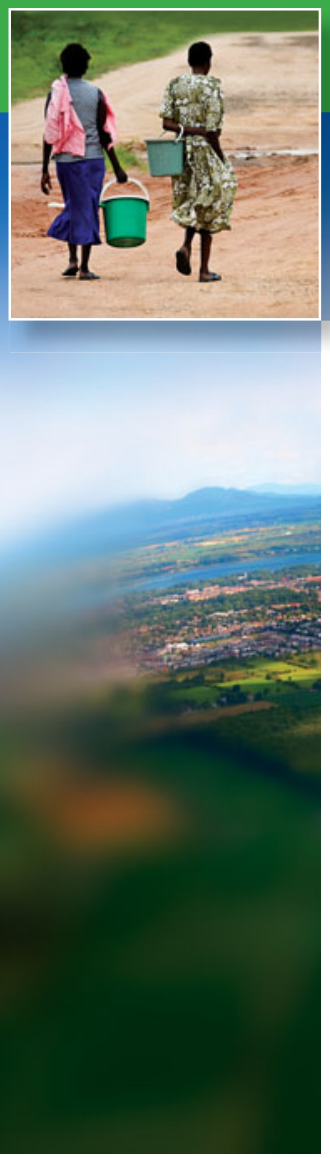

\title{
Human health and ecotoxicological considerations in materials selection for sustainable product development
}

\author{
Oladele A. Ogunseitan and Julie M. Schoenung
}

\begin{abstract}
The cost and performance of materials have traditionally been the primary factors considered by designers of consumer products. Recent attempts to quantify the environmental sustainability of such products have stimulated the development of methods for assessing the reserves of raw materials compared to the demand for their use in manufacturing and impacts on energy resources. To a much more limited extent, these strategies also evaluate how chemical toxicity, arising from material production, use, and disposal, affects humanand environmental health. The mechanisms and adverse impacts of toxic effects vary widely at different points within material life cycles, making it difficult to establish internally consistent methods and weighting criteria for quantitative evaluation of the environmental liability of consumer products. This article reviews advances in the methodology and application of health and ecological impact assessments of materials used in consumer products and argues for a stronger integration of toxicity metrics into materials informatics databases.
\end{abstract}

\section{Introduction}

In 1983, the United Nations convened the World Commission on Environment and Development in response to increasing international concerns about the depletion of natural resources and the global decline in the environment. The Commission's 1987 report produced a widely quoted definition of sustainable development as that which "meets the needs of the present without compromising the ability of future generations to meet their own needs." " Although putting this definition into practice remains a challenge, assessing and controlling the rate at which raw materials are depleted for manufacturing has become an important focus for sustainability science. Beyond the supply of raw materials, however, the environmental and human health impacts of materials use can also impair society's ability to sustain the planet for future generations. This article highlights the need to minimize the use of and exposure to toxic chemicals and materials.

Approximately 83,000 chemicals are produced for commercial applications; many are used in widely distributed consumer products (e.g., electronics, furniture, textiles). Of these, characterizations of toxicity risks to people and the environment are available for less than $10 \%{ }^{2}$ Therefore, despite growing initiatives to substitute safer alternatives for toxic components, gaps persist in the knowledge on how to proceed. ${ }^{3}$
In response to this dearth of information, the U.S. Environmental Protection Agency (EPA) established the High Production Volume (HPV) Challenge Program, a voluntary initiative that asks manufacturers to publicize information on health and environmental effects of chemicals that are either manufactured or imported in the United States in annual quantities exceeding $453 \mathrm{t}$ (1 million pounds). In contrast, the Organization for Economic Cooperation and Development (OECD) and Japan set the annual threshold for reporting on HPV chemicals at production or import of $1000 \mathrm{t}$. Approximately 2200 chemicals are included in EPA's HPV Information System, and the data represent international consensus on which chemicals to include based on 18 Screening Information Data Sets.,

The EPA develops hazard characterizations, based on data submitted by chemical manufacturers, by cross-checking registries such as the International Agency for Research on Cancer (IARC) Cancer Epidemiology Database, Extension Toxicology Network (EXTOXNET), Integrated Risk Information System (IRIS), Agency for Toxic Substances Disease Registry (ATSDR), and Toxicology Literature Online (TOXLINE) ${ }^{6}$ The HPV Information System covers 50 characteristics organized under four domains, namely, ecotoxicity (including, for example, toxicity to fish, aquatic plants, or important ecosystem processes such as biological nitrogen fixation), environmental 
fate and pathways of chemical modification (including natural biological or photochemical degradation), mammalian health effects (e.g., toxicity to reproductive, neurological, or other developmental processes), and physical/chemical properties (e.g., melting point and vapor pressure). ${ }^{7}$ However, there is no consensus on how to aggregate data in these four domains for comparative assessments of materials. Invariably, the process requires tradeoffs, for example, between a chemical that appears to be less hazardous to mammalian health but more hazardous in terms of ecotoxicity. It is unclear how best to weight these impacts to produce consistent metrics. Moreover, the data sets have numerous gaps and poorly characterized uncertainties.

The lack of international consensus on the strategy for data integration led to the establishment in 2002 of the Life Cycle Initiative (LCI) through collaboration between the United Nations Environment Programme (UNEP) and the Society for Environmental Toxicology and Chemistry (SETAC) $)^{8,9}$ (Figure 1). The consideration of toxicity impacts in the selection of alternative materials as required in phase 1 of LCI is arguably the most methodologically contentious. This article discusses methodological approaches based on Life Cycle Impact Assessment (LCIA) tools for resolving difficult questions regarding the role of toxicity in materials selection.

\section{Integration of toxicity indices into materials informatics}

Environmental legislation has targeted the use of toxic substances for decades, but known human toxicants such as lead and mercury, as well as ecologically toxic pollutants such as copper, are still used in engineered products. Furthermore, numerous new substances, including organic chemicals, are added to industrial manufacturing every year. For many of these chemicals, there is deep uncertainty about their toxicity and environmental fate. Table I reports the magnitudes of toxic releases of selected metals and organic monomers into the environment in the United States, as reported in the EPA's Toxics Release Inventory (TRI). ${ }^{14}$ The adverse consequences of toxic releases are widely recognized as diverse and costly. Coherent procedures that enable design engineers to reduce or eliminate toxic substances in their products will be a major advance toward sustainability.

In December 2006, MRS Bulletin featured a special issue on the new concept of materials informatics, defined as "the application of computational methodologies to processing and interpreting scientific and engineering data concerning materials." ${ }^{15}$ As envisioned at that time, materials informatics databases included primarily performance-related attributes and did not account for sustainability- or toxicity-related attributes in a substantial way. In fact, only the article by Cebon and Ashby in that issue mentioned such impacts, ${ }^{16}$ acknowledging the need for "environmental impact information," "recycling information," and "hazardous materials regulations." The article quantified the first two attributes simply as "energy content in MJ/kg" and "recycling fraction" and made no attempt to incorporate toxicity metrics.

Since 2006, Ashby and colleagues have further developed their materials selection method and software databases. ${ }^{17-20}$ Although their approach provides an excellent foundation for materials selection, their databases do not yet account for material toxicity, except for the inclusion of a "yes/no" indicator in response to whether the material is approved for skin and food contact by the U.S. Food and Drug Administration.

In conventional materials selection for product development, the primary purpose is to link material and function. This is achieved by focusing on selected material attributes, including mechanical, thermal, electrical, optical, and chemical properties; processing characteristics; cost and availability; and environmental consequences of use. Ideally, the attributes should be quantifiable so that they can be used to screen and rank material alternatives. The design engineer defines material function, which ultimately determines the attributes of interest.

Once the function is defined, a list of viable materials is identified and ordered according to the materials' combinations of attributes. The conventional method considers both screening and ranking to entail quantitative manipulation of attribute data sets. In practice, though, ranking often requires significant subjective judgment to consider tradeoffs among attributes, as it is
Figure 1. The international materials Life Cycle Initiative was established by the United Nations Environment Programme (UNEP) and the Society for Environmental Toxicology and Chemistry (SETAC) in response to the collective declaration of national Ministers of Environment in the year 2000. Toxicity impacts of materials, including human health and ecosystem effects, are an essential part of the Life Cycle Impact Assessment component. 
Table I. Environmental releases (2009) and human health toxicity indices for selected chemicals. , $^{\mathrm{b}}$

\begin{tabular}{|c|c|c|c|c|c|c|}
\hline & \multirow{2}{*}{$\begin{array}{l}\text { Total TRI }{ }^{10} \\
\text { releases in } \\
2009(\mathrm{~kg})\end{array}$} & \multicolumn{3}{|c|}{ Human exposure limits } & \multirow[t]{2}{*}{ IARC classification ${ }^{\mathrm{d}, 13}$} & \multirow[t]{2}{*}{ NTP classification } \\
\hline & & PEL $\left(\mathrm{mg} / \mathrm{m}^{3}\right)$ & $\operatorname{TLV}\left(\mathrm{mg} / \mathrm{m}^{3}\right)$ & $\operatorname{REL}\left(\mathrm{mg} / \mathrm{m}^{3}\right)$ & & \\
\hline \multicolumn{7}{|c|}{ Metals } \\
\hline Aluminum & $11,400,000$ & 5 & 1 & 10 & - & - \\
\hline Antimony & 444,000 & 0.5 & 0.5 & 0.5 & - & - \\
\hline Arsenic & 339,000 & 0.01 & 0.01 & - & Group 1 & Known carcinogen \\
\hline Barium & $2,310,000$ & 0.5 & 0.5 & 0.5 & - & - \\
\hline Beryllium & 4730 & 0.002 & 0.00005 & - & Group 1 & Known carcinogen \\
\hline Cadmium & 183,000 & 0.005 & 0.002 & 0.1 & Group 1 & Known carcinogen \\
\hline Chromium & $3,610,000$ & 0.5 & 0.5 & 0.5 & Group 3 & - \\
\hline Cobalt & 135,000 & 0.1 & 0.02 & 0.05 & Group 2B & - \\
\hline Copper & $4,440,000$ & 0.1 & 0.2 & 0.1 & - & - \\
\hline Lead & $6,480,000$ & 0.05 & 0.05 & 0.05 & Group 2B & Anticipated carcinogen \\
\hline Manganese & $6,420,000$ & - & 0.2 & 1 & - & - \\
\hline Mercury & 56,000 & - & 0.025 & 0.05 & Group 3 & - \\
\hline Nickel & $2,330,000$ & 1 & 1.5 & 0.015 & Group 2B & Anticipated carcinogen \\
\hline Selenium & 65,000 & 0.2 & 0.2 & 0.2 & Group 3 & - \\
\hline Silver & 62,000 & 0.01 & 0.1 & 0.01 & - & - \\
\hline Thallium & 171 & 0.1 & 0.1 & 0.1 & - & - \\
\hline Vanadium & 945,000 & - & - & - & - & - \\
\hline Zinc & $5,400,000$ & - & - & - & - & - \\
\hline \multicolumn{7}{|c|}{ Organic monomers } \\
\hline Acrylonitrile & $1,992,000$ & - & 4.3 & - & Group 2B & Anticipated carcinogen \\
\hline Bisphenol A & 563,000 & - & - & - & - & - \\
\hline 1,3-Butadiene & 533,000 & 2.21 & 4.4 & - & Group 1 & Known carcinogen \\
\hline Ethylene & $7,302,000$ & - & 230 & - & Group 3 & - \\
\hline Propylene & $4,870,000$ & - & 860 & - & Group 3 & - \\
\hline Styrene & $9,059,000$ & - & 85 & 215 & Group 2B & - \\
\hline Vinyl chloride & 177,000 & - & 2.6 & - & Group 1 & Known carcinogen \\
\hline
\end{tabular}

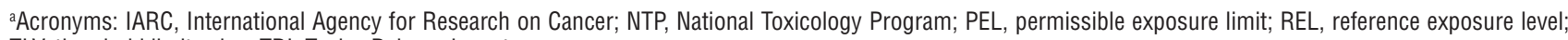
TLV, threshold limit value; TRI, Toxics Release Inventory.

${ }^{\mathrm{b} C}$ Cells highlighted in rose contain quantitative or qualitative information sufficient to trigger caution in using the corresponding chemicals in manufacturing. cHigh values are preferred for PEL, TLV, and REL.

${ }^{\mathrm{d} T h e}$ specific IARC group classifications are as follows: Group 1, carcinogenic to humans; Group 2A, probably carcinogenic to humans; Group 2B, possibly carcinogenic to humans; Group 3, not classifiable as to carcinogenicity to humans; and Group 4, probably not carcinogenic to humans.

not generally possible to identify one material that is best in all aspects.

For sustainable product design, material toxicity data must be incorporated into the screening and ranking processes. Figure 2 illustrates how such data might be integrated into the progression from chemical inventory to materials formulation and product development. In this scheme, assessment and selection of an alternative material can be triggered by information on toxicity, including risks during manufacturing (occupational exposures), product use (general population exposures), and ultimate disposal into the environment at the end of the useful product lifetime (ecotoxicological and human health impacts).

\section{Human health impacts and ecotoxicity considerations}

In the United States, hazard data are reported in material safety data sheets (MSDSs), which focus on occupational exposure limits and physical traits such as flammability and explosiveness. The potential human health concerns identified in MSDSs 


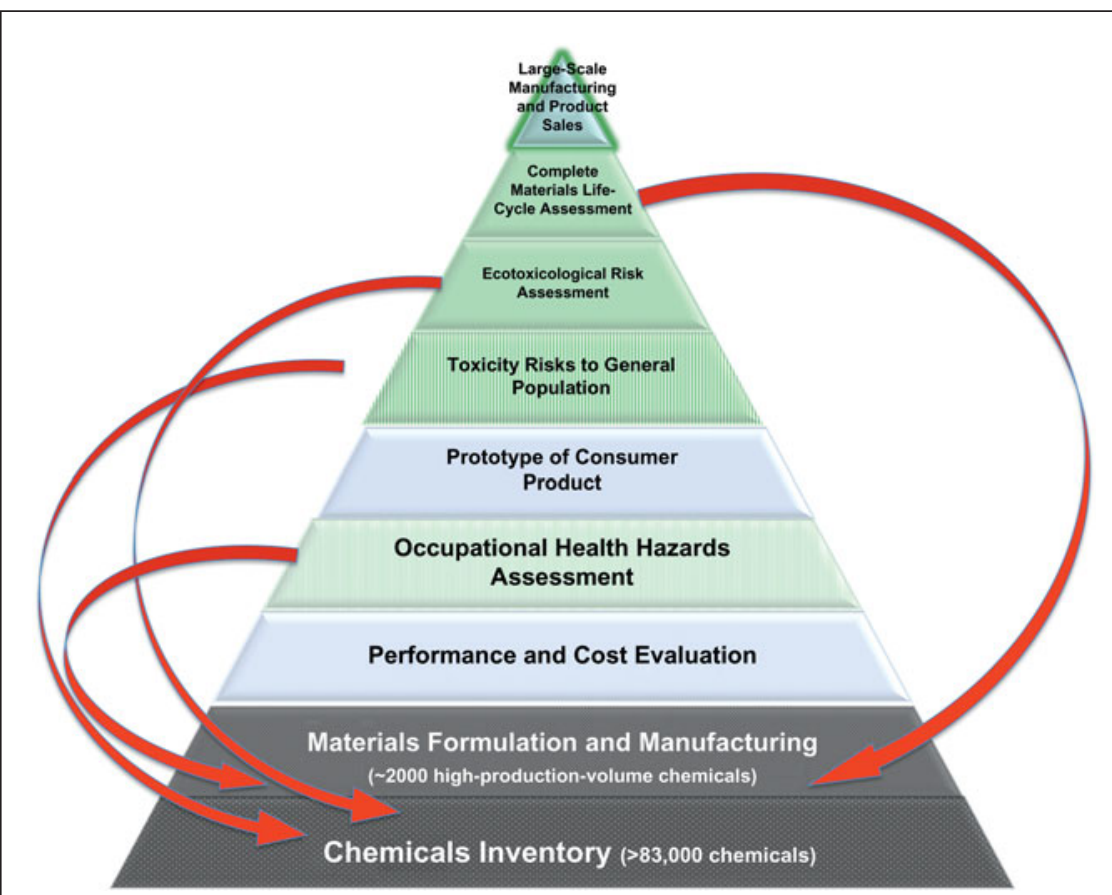

Figure 2. Proposed scheme for integrating toxicity risk assessment data into materials informatics during the manufacture of widely distributed consumer products. Red arrows signify triggers for returning to initial steps to identify less toxic alternatives based on cautionary data gathered through screening processes as product development advances. Such triggers can result from information on toxicity including risks during manufacturing (occupational exposures), product use (general population exposures), and ultimate disposal into the environment (ecotoxicological impacts).

are based on the most sensitive adverse health effects reported in the toxicological literature. Published REL values typically include margins of safety, such that exposure of human populations to chemical levels that exceed the REL does not necessarily mean that adverse health impacts will occur. Because PELs, TLVs, and RELs capture different aspects of the intersection of chemical toxicity and human exposure, it is deemed valuable to develop integrative approaches through which all three measures are used to generate a more robust index of risk when screening and ranking material alternatives relative to their potential for adverse human health effects.

Measures of potential human health impact have also been developed that are specific to cancer causation, or carcinogenicity, reflecting the high societal investment in curbing such diseases. In the laboratory, carcinogenicity is assessed most often through long-term rodent studies. ${ }^{21}$ Although toxicological tests can quantitatively measure acute toxicity, clarifying potential chronic effects requires long-term monitoring of health and, ultimately, a full pathological analysis of the animal tissues and organs.

Substantial time and resources are needed to fully characterize the carcinogenic potential of a substance, and data availability can be prob-

provide a reasonable template, but a compilation of MSDS data across multiple material options does not currently exist. We provide in Table I such an aggregation, derived from sources independent of the material suppliers, of hazard-trait values for a select group of metals and monomers.

Based on the data in Table I, it is apparent that the three attributes considered, permissible exposure limit (PEL), threshold limit value (TLV), and reference exposure level (REL), do not rank the materials equivalently. For instance, the four metals of greatest concern when selected on the basis of PEL are beryllium, cadmium, arsenic, and silver. Although beryllium, cadmium, and arsenic are also prioritized by TLV, cobalt is now fourth on the list. The REL values prioritize silver and nickel, followed by cobalt, lead, and mercury.

These differences in priority are to be expected because these three quantitative measures of occupational hazard derive from differing objectives. Specifically, PEL defines the legal limit in the United States for exposure of an employee to a chemical substance or physical agent, typically as a time-weighted average, whereas TLV is the level to which it is believed a worker can be exposed to a chemical substance day after day for a working lifetime without adverse health effects. In comparison, REL, the concentration at or below which adverse health effects are not likely to occur, is intended to establish a reference point to gauge potential effects over a lifetime of exposure. RELs account for particularly susceptible subpopulations and lematic. Furthermore, interpretation of results requires extensive training in toxicology and related subdisciplines of public health. Moreover, despite the tedious and expensive process of generating chemical toxicity profiles based on animal studies, uncertainties remain in how to establish safety thresholds for human and ecological health. ${ }^{22}$ It is common to summarize the results using simplified carcinogenic classification schemes, two of which are briefly described here.

The IARC, part of the World Health Organization (WHO), publishes the series Monographs on the Evaluation of Carcinogenic Risks to Humans, which has been influential in the classification of carcinogens. ${ }^{23}$ During the classification process, interdisciplinary working groups review published toxicity studies and evaluate the weight of evidence that exposure to a given substance can potentially cause cancer in humans. On the basis of these reviews, substances are assigned to one of five groups based on carcinogenic risk.

The National Toxicology Program (NTP) of the U.S. Department of Health and Human Services produces a biennial report on carcinogens that includes newly reviewed substances as well as all those listed previously. ${ }^{11}$ This scientific and public-health document identifies and discusses agents, substances, mixtures, or exposure circumstances that could pose a carcinogenic hazard to populations. The NTP classifies carcinogens into only two groups: those that are known to be human carcinogens and those that are reasonably anticipated to be human carcinogens. 
These two classification schemes can be used to screen and rank material alternatives, as shown in Table I. They are consistent for known carcinogens but exhibit some discrepancies for anticipated carcinogens. Thus, the recommendation is to use multiple data sets for a more robust analysis.

Beyond human health concerns, potential impacts to the environment must also be addressed in materials selection. Table II provides information on two ecological toxicity indices for the materials considered previously. The ecotoxicological indices are the $\mathrm{EC}_{50}$ value, which is the effective concentration of a substance in water that will cause irreversible damage to one-half of a population, and the fish bioconcentration factor

\begin{tabular}{|c|c|c|}
\hline Metal & $\mathrm{EC}_{50}{ }^{24}(\mathrm{mg} / \mathrm{L})$ & Fish BCF \\
\hline Aluminum & - & - \\
\hline Antimony & 2.94 & $300^{25}$ \\
\hline Arsenic & 1.78 & $4^{26}$ \\
\hline Barium & 71.94 & $100^{25}$ \\
\hline Beryllium & 0.49 & $100^{25}$ \\
\hline Cadmium & 0.86 & $366^{26}$ \\
\hline Chromium & 3.91 & $2^{26}$ \\
\hline Cobalt & 3.96 & - \\
\hline Copper & 0.13 & - \\
\hline Lead & 3.84 & $155^{26}$ \\
\hline Manganese & - & - \\
\hline Mercury & 0.11 & $5000^{26}$ \\
\hline Nickel & 0.88 & - \\
\hline Selenium & 2.64 & $50,000^{25}$ \\
\hline Silver & 0.02 & - \\
\hline Thallium & 2.81 & $100,000^{25}$ \\
\hline Vanadium & 0.86 & - \\
\hline Zinc & 1.21 & $2000^{25}$ \\
\hline Acrylonitrile & 21.63 & $1.68^{25}$ \\
\hline Bisphenol A & - & - \\
\hline 1,3-Butadiene & - & $19^{27}$ \\
\hline Ethylene & - & - \\
\hline Propylene & - & - \\
\hline Styrene & 21.30 & $13.5^{25}$ \\
\hline Vinyl chloride & - & $7^{25}$ \\
\hline
\end{tabular}

aDefinitions: $\mathrm{EC}_{50}$, effective concentration of a substance in water that will cause irreversible damage in one-half of a population; BCF, bioconcentration factor by which the concentration of a substance in fish exceeds its concentration in the surrounding water. High values are preferred for $\mathrm{EC}_{50}$, and low values are preferred for BCF.

${ }^{b}$ Cells highlighted in rose contain values sufficient to trigger caution in using the corresponding chemicals in manufacturing.
(BCF), which is the ratio by which the concentration of a substance in fish is enhanced relative to the surrounding water and thus a measure of persistence and bioaccumulation potential.

On the basis of $\mathrm{EC}_{50}$ values, silver, mercury, and copper are of particular concern, whereas the fish BCFs for thallium (100,000), selenium (50,000), mercury (5000), and zinc (2000) are disturbingly high. In general, BCFs greater than 1000 are considered high, and values less than 250 represent low to negligible risk, with intermediate values being considered moderately risky. The bioaccumulation of metals in fish tissue can produce cascading impacts up the food chain, ultimately affecting wildlife and human health, as demonstrated for mercury in edible fish. ${ }^{28}$ Again, the recommended approach is to use multiple indices to obtain a more complete representation of material hazards.

A new classification scheme, developed by the United Nations and called the Globally Harmonized System of Classification and Labelling of Chemicals (GHS), is intended to eliminate discrepancies resulting from nation-to-nation variability and thereby replace classification schemes such as IARC and NTP. With GHS, it will ideally be possible to systematically classify chemicals on the basis of multiple attributes such as carcinogenicity, as well as acute and chronic ecotoxicity. ${ }^{29}$ Because of its novelty, however, few substances have yet been fully classified within the GHS system. ${ }^{30}$

\section{Integrative approaches}

In addition to hazard-trait values and classification schemes, such as those described in the preceding section, a variety of tools have been developed that integrate several metrics to generate numerical indicators of human health and ecological toxicity. These methods include

- TRACI, Tool for the Reduction and Assessment of Chemical and Other Environmental Impacts (EPA); ${ }^{31,32}$

- USEtox $^{\mathrm{TM}}$, the UNEP-SETAC consensus toxicity mode1; ${ }^{33,34}$

- CHEMS-1, Chemical Hazard Evaluation for Management Strategies (EPA); ${ }^{35}$ and

- TPI, Toxic Potential Indicator (developed by the Fraunhofer Institut für Zuverlässigkeit und Mikrointegration, Hannover, Germany). ${ }^{36}$

A comparison of the main features of these methods is presented in Table III. Unlike the binned cancer classification schemes described in the preceding section, these four methods provide quantitative values unique to each substance (Table IV). To highlight the value of such methods, we describe and compare TRACI and TPI. TRACI represents a set of lifecycle impact-assessment modules that generate three characterization factors [cancer potential, noncancer potential (other human diseases), and ecotoxicity] in each of four environmental media (air, water, ground-surface soil, and root-zone soil). Six of these 12 factors are listed in Table IV for selected TRI metals. ${ }^{37}$

To produce quantitative measures of cancer and noncancer risks associated with specific chemicals, TRACI relies on a closed-system, steady-state chemical fate and exposure assessment model called CalTOX, developed by the Exposure 


\begin{tabular}{|c|c|c|c|c|}
\hline Method & TRACI & USEtox & CHEMS-1 & TPI \\
\hline Application & $\begin{array}{l}\text { Life-cycle impact } \\
\text { assessment }\end{array}$ & $\begin{array}{l}\text { Life-cycle impact } \\
\text { assessment }\end{array}$ & $\begin{array}{l}\text { Hazard-based chemical } \\
\text { prioritization }\end{array}$ & $\begin{array}{l}\text { Comparative materials } \\
\text { selection }\end{array}$ \\
\hline Complexity & High & High & Medium-high & Medium \\
\hline Transparency & Medium & Medium & High & High \\
\hline $\begin{array}{l}\text { Number of substances } \\
\text { covered }\end{array}$ & 932 & 3094 & $\begin{array}{l}\text { Depends on toxicity data } \\
\text { availability }\end{array}$ & $\begin{array}{c}\text { Depends on toxicity data } \\
\text { availability }\end{array}$ \\
\hline Metals/metal compounds & $\begin{array}{l}\text { Metals (18 metal types } \\
\text { listed) }\end{array}$ & $\begin{array}{c}\text { Metals (18 metal types } \\
\text { listed) }\end{array}$ & $\begin{array}{c}\text { Depends on toxicity data } \\
\text { availability }\end{array}$ & $\begin{array}{l}\text { Depends on toxicity data } \\
\text { availability }\end{array}$ \\
\hline Polymers & Some monomers & Some monomers & $\begin{array}{l}\text { Depends on toxicity data } \\
\text { availability }\end{array}$ & $\begin{array}{c}\text { Depends on toxicity data } \\
\text { availability }\end{array}$ \\
\hline
\end{tabular}

aModels: TRACI, Tool for the Reduction and Assessment of Chemical and Other Environmental Impacts; USEtox, UNEP-SETAC consensus toxicity mode1; CHEMS-1, Chemical Hazard Evaluation for Management Strategies; and TPI, Toxic Potential Indicator.

\begin{tabular}{|c|c|c|c|c|c|c|c|}
\hline \multirow[t]{2}{*}{ Metal } & \multicolumn{2}{|c|}{ TRACI cancer potential } & \multicolumn{2}{|c|}{ TRACI noncancer potential } & \multicolumn{2}{|c|}{ TRACI ecotoxicity potential } & \multirow{2}{*}{$\begin{array}{c}\text { TPI score } \\
\left(\mathrm{mg}^{-1}\right)\end{array}$} \\
\hline & Air & Water & Air & Water & Air & Water & \\
\hline Aluminum & - & - & 11,174 & 20 & 7030 & 1844 & 1.36 \\
\hline Antimony & - & - & $2,801,491$ & 4206 & - & - & 33.33 \\
\hline Arsenic & 8497 & 282 & 469,379 & 13,502 & 209 & 246 & 72.79 \\
\hline Barium & - & - & 18,046 & 57 & - & - & 1.99 \\
\hline Beryllium & 12 & $1.1 \times 10^{-46}$ & 167,536 & 1047 & - & - & 36.32 \\
\hline Cadmium & 25 & $5.4 \times 10^{-49}$ & 387,350 & $2,013,978$ & 6 & 10 & 85.05 \\
\hline Chromium & 70 & $5.6 \times 10^{-46}$ & 57,677 & 583 & 1049 & 780 & 1.20 \\
\hline Cobalt & - & - & 29,043 & $2.6 \times 10^{-43}$ & - & - & 35.35 \\
\hline Copper & - & - & 13,214 & 5903 & 21,665 & 11,537 & 4.48 \\
\hline Lead & 58 & $1.6 \times 10^{-47}$ & $2,173,733$ & $11,303,405$ & 1 & 2 & 63.42 \\
\hline Manganese & - & - & 6092 & 12 & - & - & 2.41 \\
\hline Mercury & - & - & 99,911 & 943,040 & 16 & 3114 & 78.91 \\
\hline Nickel & - & - & 71,919 & 93 & 7836 & 2671 & 38.01 \\
\hline Selenium & - & - & 71,282 & 1419 & 1528 & 1076 & 21.19 \\
\hline Silver & - & - & 39,323 & 539 & 8487 & 7535 & 4.48 \\
\hline Thallium & - & - & 208 & 16 & - & - & 66.67 \\
\hline Vanadium & - & - & 136,864 & 547 & - & - & 33.33 \\
\hline Zinc & - & - & 10,247 & 18 & 5879 & 2052 & 13.87 \\
\hline
\end{tabular}

${ }^{a}$ Acronyms: TPI, Toxic Potential Indicator; TRACI, Tool for the Reduction and Assessment of Chemical and Other Environmental Impacts; TRI, Toxics Release Inventory. 'Table cells highlighted in rose contain values sufficiently high, within the relevant risk category, to trigger caution in using chemicals for manufacturing consumer products. In general, low values are preferred for all characteristics reported in the table.

and Risk Analysis Group at Lawrence Berkeley National Laboratory. CalTOX combines the toxicity of a chemical with the amount released into the environment over a given period of time to calculate its human toxicity potential, which is expressed relative to baseline values for benzene (carcinogens) or toluene (noncarcinogens), two chemicals for which extensive toxicological data linking exposure to disease in a linear dose-response model exist. Thus, the output data are toxicity equivalencies that support comparisons of the impacts of different chemical emissions into a given environment. ${ }^{38}$ Similarly, the ecotoxicity potential outputs from TRACI represent toxicity-weighted chemical emission concentrations 
that allow for the comparison of the ecological impacts of a new chemical to those of a relatively well-characterized chemical, namely, the herbicide 2-4-dichlorophenoxyacetic acid (2,4-D).

In comparison, TPI requires the user to provide selected hazard data (i.e., for human health impact, environmental impact, and physical safety concerns) from which it derives a single indicator by integrating metrics for human health, ecological health, and physical/safety traits. ${ }^{39}$ To generate TPI scores such as those reported in Table IV, one must input data from original, authoritative, and valid sources.

All available alternative assessment techniques encounter methodological limitations, including complexity, lack of transparency, and limited data sets even for materials used frequently in engineered products (metals, polymers). Despite these limitations, these methods can be used to incorporate material toxicity into the screening and ranking of materials and thereby enable sustainable product design.

In one example, Lam and colleagues used TRACI to evaluate toxic releases from printed circuit board manufacturing facilities as a strategy to avoid pollution. ${ }^{40}$ Although the environmental releases of toxic chemicals such as methanol, glycol ethers, and dimethylformamide dominated reported air and water emissions, toxicity potentials and risk-screening scores showed that lead and copper actually generate the highest environmental impacts. Therefore, effective strategies for pollution prevention include recovering copper from spent etchant and employing lead-free substitutes for solder and other components.

Materials substitutions to reduce toxic impacts have also been studied for specific electronic products. For example, Lim and Schoenung ${ }^{41}$ evaluated the end-of-life toxicity potential from the heavy-metal content in flat-panel display devices that are replacing conventional cathode-ray-tube (CRT) devices. That study focused on plasma and liquid-crystal-display (LCD) televisions, LCD computer monitors, and laptop computers. The human health and ecotoxicity potentials were evaluated by combining data on the respective heavy-metal contents and the characteristic factors in TRACI. The results showed that the leading contributors to the toxicity potentials are lead, arsenic, copper, and mercury. Although the heavy-metal content in newer flat-panel display devices produces lower human health toxicity potentials than that in CRTs, the newer devices are worse in terms of ecological toxicity impacts because of the mercury in the fluorescent backlights in LCD televisions and the copper in plasma televisions.

Similar integrative approaches have been used to evaluate cellular phones and light-emitting diodes to pinpoint specific material constituents that exceed hazard thresholds specified in risk-based policy regulations. These materials could be targeted by product designers and manufacturers for substitutions to make safer, environmentally sustainable products. ${ }^{42-44}$ In concert, these studies demonstrate the usefulness of integrative methods such as TRACI and TPI that generate simple quantitative values combining both human health and ecotoxicological impact rankings. However, much research remains to be done to make such models consistent in terms of the quality and format of raw data inputs and the translation of the output into guidance for the selection of sustainable alternative materials for designers and manufacturers of consumer products.

\section{Conclusions}

Whereas the selection of materials for use in products has traditionally focused solely on cost and performance characteristics, sustainability must also become an important factor. Avoiding human health and ecological impacts requires their assessment at the level of materials selection in the early stages of product design and manufacturing. For such strategies to become viable, toxicity metrics need to be integrated into materials informatics frameworks in a transparent way that supports the selection of safer alternatives.

\section{References}

1. Report of the World Commission on Environment and Development. Our Common Future (Annex to Document A/42/427, Oxford University Press, Oxford, UK, 1987).

2. Toxic Substances Control Act Chemical Substance Inventory (U.S. Environmental Protection Agency, Washington, DC), www.epa.gov/opptintr/existingchemicals/ pubs/tscainventory/ (accessed November 2011).

3. S.O. Hansson, L. Molander, C. Rudén, Regul. Toxicol. Pharmacol. 59, 454 (2011). 4. High Production Volume (HPV) Challenge Program (U.S. Environmental Protection Agency, Washington, DC), www.epa.gov/chemrtk/ (accessed November 2011). 5. High Production Volume (HPV) Challenge Program: Guidance Documents (U.S. Environmental Protection Agency, Washington, DC), www.epa.gov/chemrtk/ pubs/general/guidocs.htm (accessed November 2011).

6. Risk Assessment Guidelines (U.S. Environmental Protection Agency, Washington, DC), http://cfpub.epa.gov/ncea/cfm/recordisplay. cfm?deid=55907 (accessed November 2011).

7. High Production Volume Information System (HPVIS) (U.S. Environmental Protection Agency, Washington, DC), www.epa.gov/chemrtk/hpvis/index.html (accessed November 2011)

8. Malmö Ministerial Declaration (United Nations Environment Programme, Nairobi, Kenya, 2000).

9. The Life Cycle Initiative (United Nations Environment Programme, Nairobi, Kenya), http://lcinitiative.unep.fr/ (accessed November 2011).

10. Toxics Release Inventory (TRI) Program (U.S. Environmental Protection Agency, Washington, DC), www.epa.gov/tri/ (accessed November 2011).

11. 12th Report on Carcinogens (RoC) (National Toxicology Program, Washington, DC, 2011)

12. 2009 Guide to Occupational Exposure Values (American Conference of Governmental Industrial Hygienists, Cincinnati, $\mathrm{OH}, 2009)$.

13. Agents Classified by the IARC Monographs, Volumes 1-102 (World Health Organization, Lyon, France), monographs.iarc.fr/ENG/Classification/index.php (accessed November 2011).

14. Toxics Release Inventory (TRI) Explorer: Release Reports (U.S. Environmental Protection Agency, Washington, DC), iaspub.epa.gov/triexplorer/tri_release. chemical (accessed November 2011).

15. J.R. Rodgers, D. Cebon, MRS Bull. 31 (12), 975 (2006).

16. D. Cebon, M.F. Ashby, MRS Bull. 31 (12), 1004 (2006).

17. M.F. Ashby, Materials Selection in Mechanical Design (Elsevier, Amsterdam, ed. 4, 2011).

18. M.F. Ashby, A. Miller, F. Rutter, C. Seymour, U.G.K. Wegst, The CES EduPack Eco Selector-Background Reading (Granta Design, Cambridge, UK, 2009).

19. M. Ashby, P. Coulter, N. Ball, C. Bream, The CES EduPack Eco Audit Tool-A White Paper (Granta Design, Cambridge, UK, 2009).

20. Granta CES 2012 Eco Selector (Granta Design Ltd., Cambridge, UK), www. grantadesign.com/products/ces/ (accessed November 2011).

21. OECD Guidelines for Testing of Chemicals. Section 4: Health Effects (Organisation for Economic Co-operation and Development, Paris, France, 2011).

22. D. Krewski, M.E. Anderson, E. Mantus, L. Zeise, Risk Anal. 29 (4), 474 (2009).

23. IARC Monographs on the Evaluation of Carcinogenic Risks to Humans: Preamble (World Health Organization, Lyon, France, 2006).

24. ECOTOX Database (U.S. Environmental Protection Agency, Washington, DC), cfpub.epa.gov/ecotox/ (accessed November 2011). 
25. National Recommended Water Quality Criteria (U.S. Environmental Protection Agency, Washington, DC), http://water.epa.gov/scitech/swguidance/standards/ current/index.cfm (accessed November 2011).

26. Technical Support Document for Exposure Assessment and Stochastic Analysis (Office of Environmental Health Hazard Assessment, Sacramento, CA, 2000), Appendix H: Fish Bioconcentration Factors.

27. 1,3-Butadiene Human Health Aspects (Concise International Chemical Assessment Document 30, World Health Organization, Geneva, Switzerland, 2001).

28. Mercury Levels in Commercial Fish and Shellfish (1990-2010) (U.S. Food and Drug Administration, Washington, DC), www.fda.gov/Food/FoodSafety/ProductSpecificlnformation/Seafood/FoodbornePathogensContaminants/Methylmercury/ ucm115644.htm (accessed November 2011).

29. A Guide to The Globally Harmonized System of Classification and Labelling of Chemicals (GHS) (Occupational Safety and Health Administration, Washington, DC, 2004), section 3.2.

30. Globally Harmonized System of Classification and Labelling of Chemicals (GHS) (United Nations, New York), live.unece.org/trans/danger/publi/ghs/ghs rev02/02files_e.html (accessed November 2011).

31. J.C. Bare, G.A. Norris, D.W. Pennington, T.E. McKone, J. Ind. Ecol. 6, 49 (2003).

32. J.C. Bare, Clean Technol. Environ. Policy 12, 341 (2010).

33. R.K. Rosenbaum, T.M. Bachmann, L.S. Gold, M.A. Huijbregts, O. Jolliet,

R. Juraske, A. Koehler, H.F. Larsen, M. MacLeod, M. Margni, T.E. McKone,
J. Payet, M. Schuhmacher, D. van de Meent, M.Z. Hauschild, Int. J. Life Cycle Assessment 13, 532 (2008)

34. M.A. Huijbregts, M.Z. Hauschild, O. Jolliet, M. Margni, T.E. McKone, D. van de Meent, USEtox ${ }^{T M}$ User manual (USEtox ${ }^{T M}$ Team, 2010).

35. M.B. Swanson, G.A. Davis, L.E. Kincaid, T.W. Schultz, J.E. Bartmess, S.L. Jones, E.L. George, Environ. Toxicol. Chem. 16, 372 (1997).

36. N.F. Nissen, I. Griese, A. Middendorf, J. Müller, H. Pötter, H. Reichl, in Proceedings of the 1998 IEEE International Symposium on Electronics and the Environment (IEEE Press, New York, 1998), pp. 106-111.

37. Tool for the Reduction and Assessment of Chemical and Other Environmental Impacts (TRACI): User's Guide and System Documentation (Report EPA/600/ R-02/052, U.S. Environmental Protection Agency, Washington, DC, 2003).

38. E.G. Hertwich, S.F. Mateles, W.S. Pease, T.E. McKone, Environ. Toxicol. Chem. 20 (4), 928 (2001)

39. Toxic Potential Indicator Calculator (Fraunhofer Institut für Zuverlässigkeit und Mikrointegration, Hannover, Germany), www.izm.fraunhofer.de/EN/abteilungen/ere/ dienstleistungen/izmeetoolbox/TPICalculator.jsp (accessed November 2011).

40. C.W. Lam, S.-R. Lim, J.M. Schoenung, J. Hazard. Mater. 189, 315 (2011).

41. S.-R. Lim, J.M. Schoenung, J. Hazard. Mater. 177, 251 (2010).

42. J.D. Lincoln, O.A. Ogunseitan, J.-D. Saphores, A.A. Shapiro, Environ. Sci. Technol. 41 (7), 2572 (2007)

43. S.-R. Lim, J.M. Schoenung, Waste Manage. 30, 1653 (2010).

44. S.-R. Lim, D. Kang, O.A. Ogunseitan, J.M. Schoenung, Environ. Sci. Technol. 45, 320 (2011)
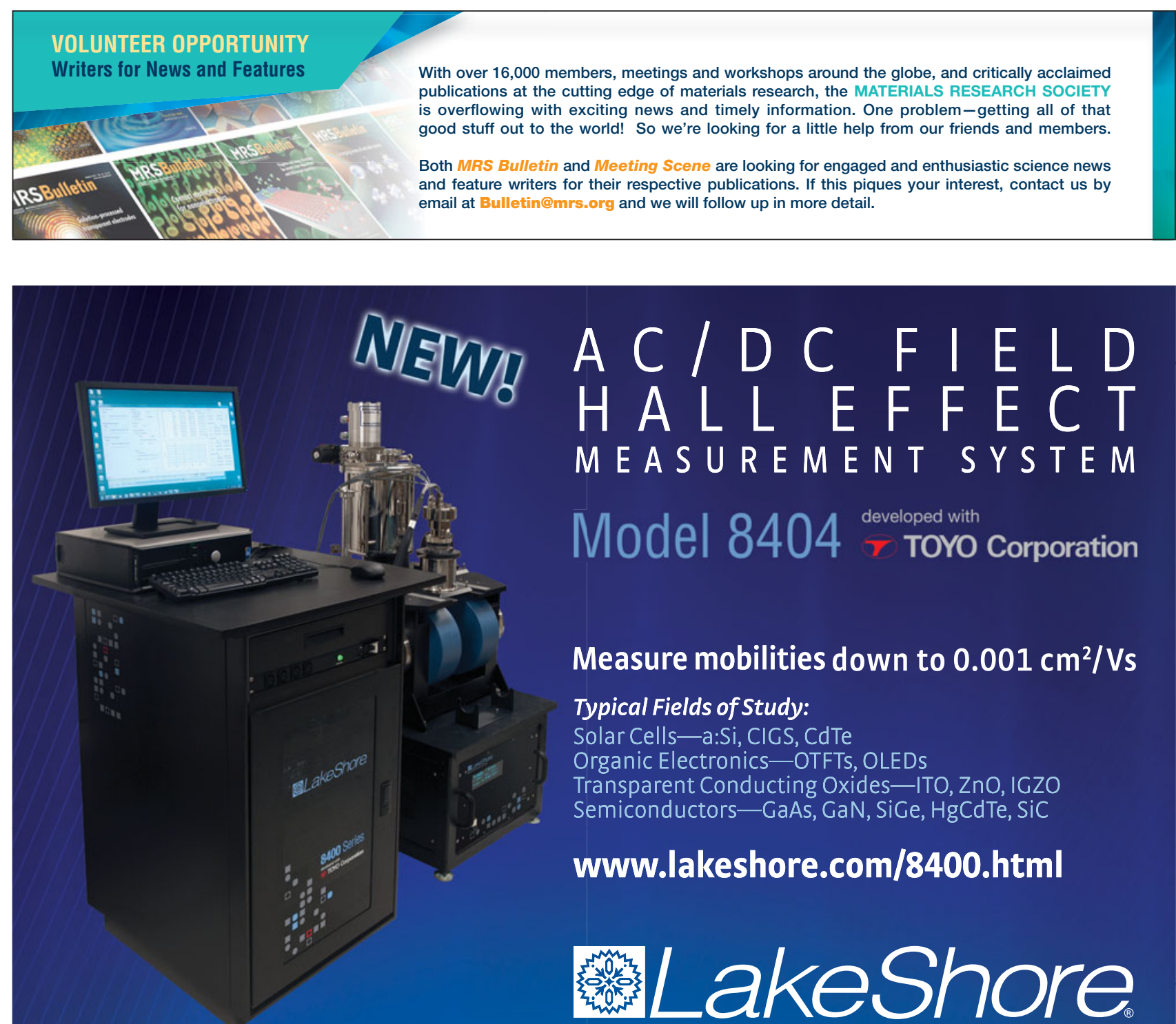

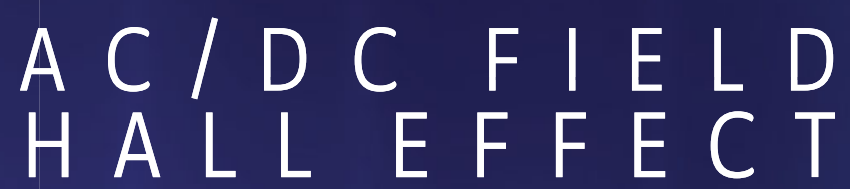

MEASUREMEN T S Y S T E M

Model $8404 \stackrel{\text { developed with }}{\tau}$ TOYO Corporation

Measure mobilities down to $0.001 \mathrm{~cm}^{2} / \mathrm{Vs}$

Typical Fields of Study:

Solar Cells-a:Si, CIGS, CdTe

Organic Electronics-OTFTs, OLEDs

Transparent Conducting Oxides-ITO, ZnO, ICZO

Semiconductors - GaAs, GaN, SiGe, HgCdTe, SiC

www.lakeshore.com/8400.html

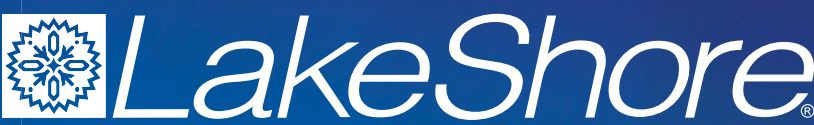




\section{J.A. Woollam Co., Inc.}

Ellipsometry Solutions ${ }^{\text {sm }}$ for your Thin Film Characterization.

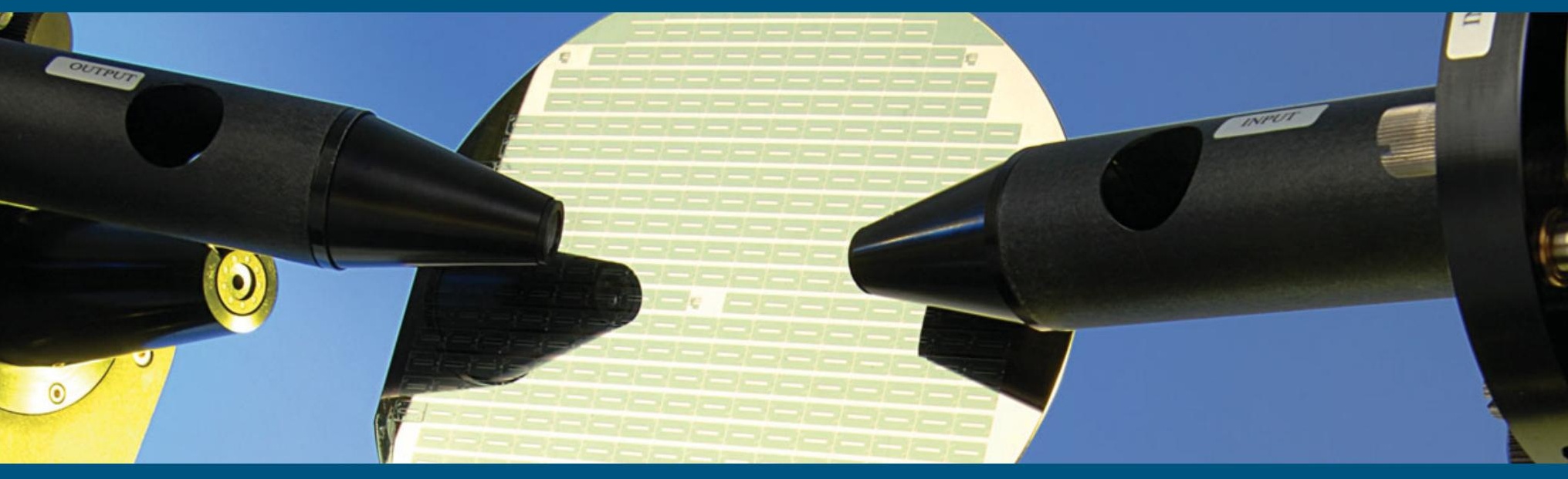

J.A. Woollam Co. has the world's widest variety of Spectroscopic Ellipsometers with $\mathbf{8}$ different models to non-destructively characterize thin film thickness and optical constants. After twenty-four years, over 15,000 samples characterized in our lab, and over 140 patents - we are the Ellipsometry Experts.

\section{Ellipsometry Solutions}

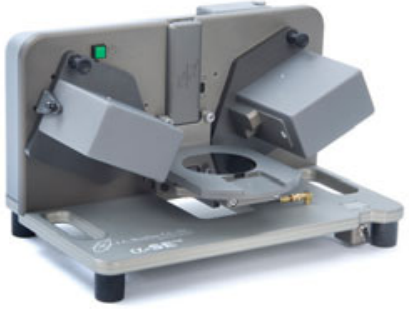

alpha-SE ${ }^{\circledR}$

A great solution for routine measurements of thin film thickness and refractive index. Designed for ease-ofuse: simply mount a sample, choose the model that matches your film, and press "Measure". Results are yours within seconds.

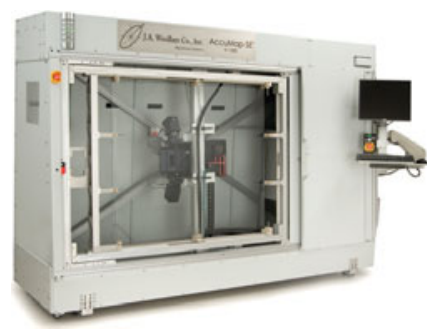

\section{AccuMap-SE ${ }^{\circledR}$}

Characterize thin film uniformity of large panels with ease. The AccuMap-SE combines a high-speed M-2000 ellipsometer, wide spectral range, and fast mapping for large panels. Perfect for photovoltaic or flat panel display thin films.

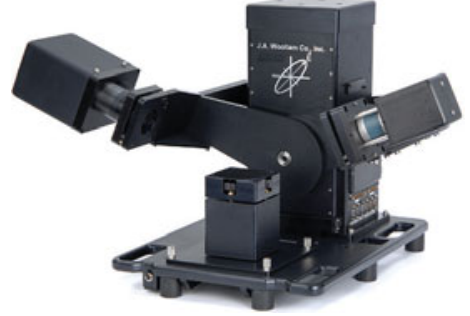

M-2000 ${ }^{\circledR}$

The M-2000 line of ellipsometers is engineered to meet the diverse demands of thin film characterization. An advanced optical design, wide spectral range, and fast data acquisition make it extremely powerful for in situ, in-line and ex situ applications.

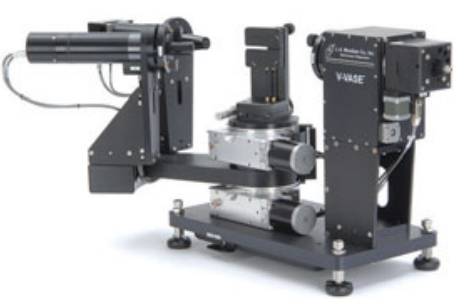

VASE

The VASE is our most accurate and versatile research ellipsometer for all types of materials: semiconductors, dielectrics, organics, metals, multi-layers, and more. Now available with the widest spectral range from ultraviolet to infrared. 